\title{
Stent angioplasty of narrowed portocaval shunt in Budd Chiari syndrome: a case report
}

\author{
Nilesh Doctor*1, Vidhyachandra Gandhi ${ }^{1}$, Sharad Shah², Maharra Hussain ${ }^{1}$, \\ Shaji Marar ${ }^{3}$ and Sujith Philip ${ }^{1}$
}

Address: ${ }^{1}$ Department of Gastrointestinal Surgery, Jaslok Hospital \& Research Centre, Mumbai, India, ${ }^{2}$ Department of Gastroenterology, Jaslok Hospital \& Research Centre, Mumbai, India and ${ }^{3}$ Department of Interventional Radiology, Jaslok Hospital \& Research Centre, Mumbai, India

Email: Nilesh Doctor* - drnileshbela@gmail.com; Vidhyachandra Gandhi - drgandhivv@yahoo.co.in;

Sharad Shah - sharadshah2000@yahoo.com; Maharra Hussain - maharrahussain@rediffmail.com; Shaji Marar - shajipmarar@gmail.com;

Sujith Philip - sujithphilip@gmail.com

* Corresponding author

Published: I January 2009

Cases Journal 2009, 2:1 doi:10.1186/1757-1626-2-1

This article is available from: http://www.casesjournal.com/content/2/l/I

(c) 2009 Doctor et al; licensee BioMed Central Ltd.

This is an Open Access article distributed under the terms of the Creative Commons Attribution License (http://creativecommons.org/licenses/by/2.0), which permits unrestricted use, distribution, and reproduction in any medium, provided the original work is properly cited.
Received: I December 2008

Accepted: I January 2009

\begin{abstract}
Background: Hepatic vein thrombosis (Budd-Chiari Syndrome) is a rare disorder resulting from an obstruction to the outflow of blood from the liver. Early decompression is needed to prevent liver dysfunction and death. Radiological intervention includes angioplasty of stenosis and webs and the placement of transjugular intrahepatic portosystemic shunts (TIPPS). Side-to-side portacaval shunt (SSPCS) remains the gold standard for achieving good long-term results.
\end{abstract}

Case presentation: A 37-year old lady underwent side-to-side portacaval shunt for Budd Chiari syndrome. She had early shunt blockage and this was successfully treated with the placement of a metallic stent across the shunt.

Conclusion: At five years, she remains asymptomatic, with normal liver functions, no ascites, and normal flow through the stent on Colour Doppler examination.

\section{Background}

Budd-Chiari syndrome is characterized by hepatic venous outflow obstruction, which often leads to death as a result of portal hypertension and liver failure. Patients with membranous occlusion of the major hepatic veins can be treated by percutaneous placement of a metallic stent via a transjugular or transhepatic approach [1]. In patients with a significant caval obstruction caused by a hypertrophied caudate lobe, a metallic vascular stent can be placed in the narrowed tract of the inferior vena cava, before shunt surgery, by means of a transfemoral or transjugular venous approach [1]. Side to side portacaval shunts have excellent long-term results and remain the procedure of choice in some units [2]. Stents can also be used to main- tain the patency of surgical shunts that have been made to bypass the obstruction to the blood flow from the splanchnic circulation to the inferior vena cava via the liver. We report a long term follow up of stent angioplasty of a narrowed porta caval shunt in a patient with Budd Chiari Syndrome.

\section{Case presentation}

A thirty seven year old female presented with a history of progressive distension of the abdomen with pedal edema and yellow discolouration of the eyes of two weeks duration. On examination she was found to be icteric with an enlarged, firm liver and gross ascites. Liver function tests revealed a conjugated hyperbilirubinemia with mildly 
deranged transaminases and alkaline phosphatase. Ultrasonography (USG) with Colour Doppler showed an enlarged liver with a hypertrophied caudate lobe, a $1.1 \mathrm{~cm}$ portal vein with hepatopetal flow, an occluded right hepatic vein with middle and left hepatic veins patent only in their proximal parts and a patent but narrowed inferior vena cava, compressed by the caudate lobe, together with free fluid in the abdomen. Splenic and superior mesenteric veins were normal. Liver biopsy confirmed the diagnosis of Budd Chiari syndrome. Prothrombotic workup did not reveal any obvious cause for the Budd Chiari syndrome.

Transjugular venogram showed $90 \%$ narrowing of the IVC with a $14 \mathrm{mmHg}$ gradient across the narrowing and nonvisualization of the hepatic veins beyond their origins. The hepatic veins could not be cannulated, suggestive of complete occlusion at the ostia. (Figure 1:A). An $18 \times 63$ mm WALL STENT was placed across the narrowed segment in the IVC followed by balloon dilatation using a 16 $\mathrm{mm}$ balloon (Figure 1:B).

Percutaneous transhepatic venogram through the left hepatic vein under USG guidance showed the left hepatic vein was patent only in its proximal portion, the distal 2$3 \mathrm{cms}$ being completely occluded and draining through multiple collaterals. IVC stent was in situ (Figure 2). The right hepatic vein was completely occluded. The middle hepatic vein also showed long-segment total occlusion (> $3 \mathrm{~cm}$ ).

Recanalisation of the left hepatic vein was attempted, but failed owing to the long and fibrous nature of the occlusion. The patient then underwent a side-to-side portocaval shunt using the right external iliac vein as H-graft. Postoperative recovery was uneventful and she was anticoagu-

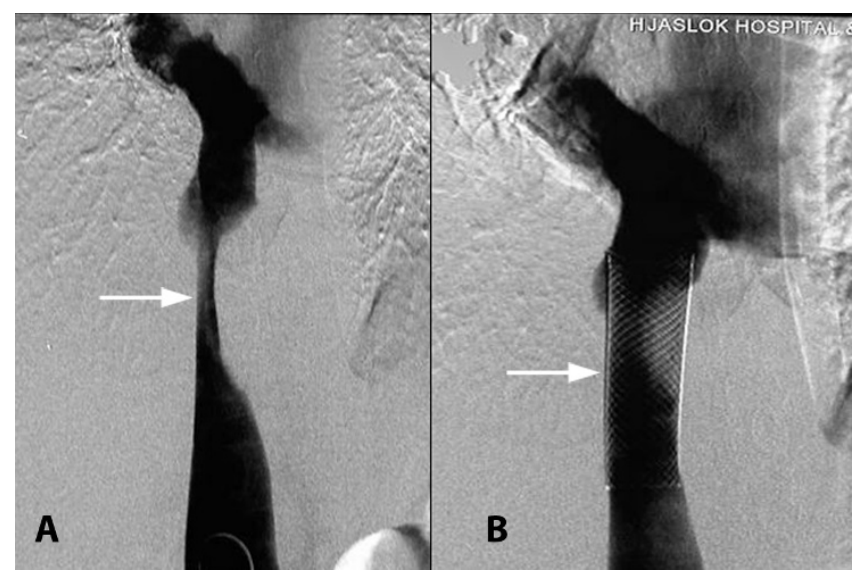

Figure I

A. Narrowed IVC with non visualization of hepatic veins. B. IVC stent in situ.

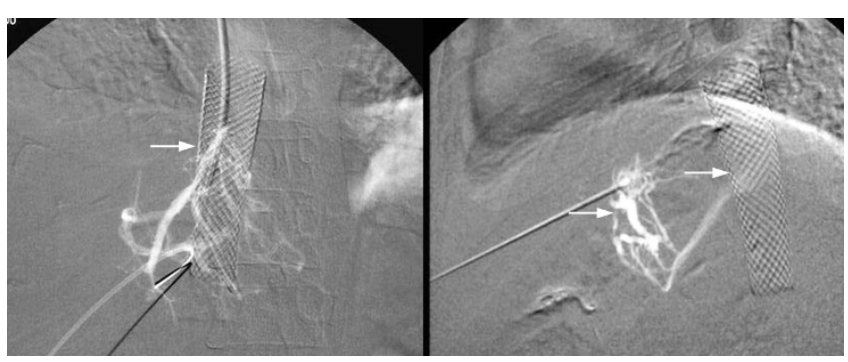

Figure 2

Percutaneous transhepatic venogram revealed left hepatic vein replaced by multiple collaterals, IVC stent in situ.

lated during that time. Six weeks after surgery, she was readmitted with pedal edema and ascites. Doppler evaluation showed patchy flow through the shunt. Venogram through a transjugular approach revealed patent IVC stent. There was narrowing of the portosystemic graft with a gradient of more than $15 \mathrm{mmHg}$ near its IVC end (Figure 3:A, B).

Considering the acute angulation of the portocaval shunt with the IVC, a transfemoral venous approach for venoplasty and stenting was thought to be more appropriate. Following predilatation of the graft with a $5 \mathrm{~mm}$ angioplasty balloon (Figure 4A), an $8 \mathrm{~mm} \times 30 \mathrm{~mm}$ selfexpanding nitinol stent was placed in the graft covering its portal and caval ends. Post dilatation was carried out by a $8 \mathrm{~mm}$ balloon. Post stenting portal venogram showed good flow through the graft into the IVC (Figure 4:B).

The portocaval gradient dropped to $<5 \mathrm{mmHg}$ post stenting. Subsequently she was anticoagulated with warfarin. The patient has been on regular follow up since then and is asymptomatic for five years.

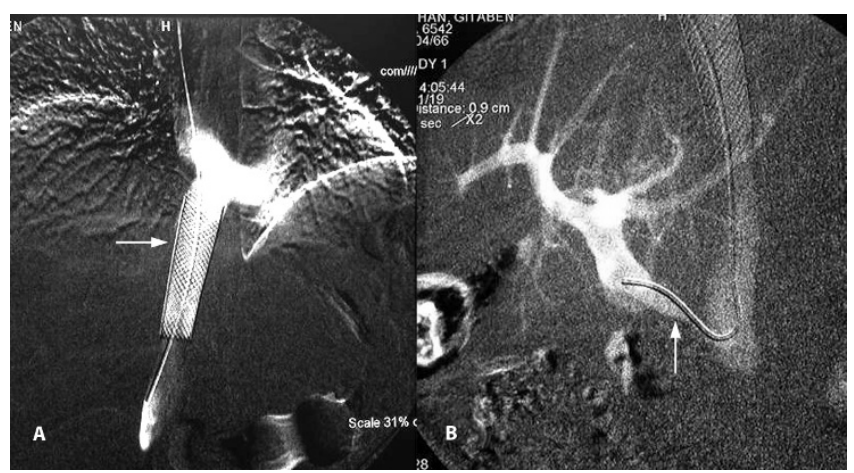

Figure 3

Transjugular venogram A. Patent IVC Stent B. Narrowed portocaval graft. 


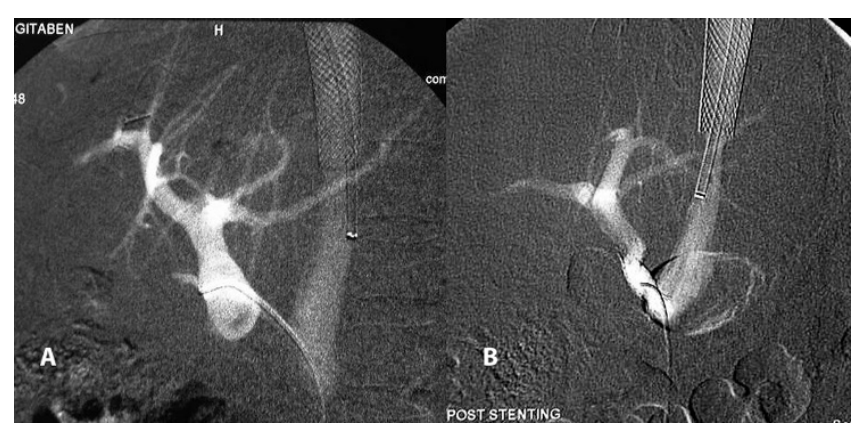

Figure 4

Transfemoral venoplasty $A$. Pre dilatation of the graft. B. Widened, patent graft post dilatation with stent in situ.

\section{Discussion}

BCS is characterized by manifestations of portal hypertension, inferior vena cava occlusion or both [1]. It produces liver damage due to intense congestion, leading to development of cirrhosis. To prevent congestion, various nonsurgical and surgical procedures have been described.

A variety of surgical procedures can be used for decompression of the liver, including mesoatrial, mesocaval and portocaval shunts and liver transplantation. If there is no thrombosis in the inferior vena cava, a side-to-side portocaval shunt (SSPCS) is the procedure of choice in the early and middle stages of the disease [2]. Direct portocaval shunts have a thrombosis rate of $0.2 \%$, compared with occlusion rates $24-53 \%$ for mesocaval shunts with synthetic grafts. However, autologous internal jugular vein grafts have patency rates comparable with those of portocaval shunts [3]. Mesoatrial shunts are preferred if there is a greater than $75 \%$ narrowing of the vena cava [4]. However, the patency rate of mesoatrial shunts is low, Slakey et al. [5] reporting a primary shunt patency rate of only $46 \%$. To improve the shunt patency Orloff et al. [2] introduced a high-flow combination shunt, consisting of a side-to side portocaval shunt and a cavoatrial shunt. Results of this combined form were promising. Orthotopic liver transplantation is indicated in patients with chronic BCS who have cirrhosis and patients with a failed portosystemic shunt procedure. It has a 5-year survival rate of $69 \%$ [6]. Blockage of the shunts performed to decompress the liver can be a life-threatening event and is usually associated with excessive variceal hemorrhage. Recently percutaneous interventional techniques, including angioplasty, fibrinolysis, Self expanding metallic stents (SEMS) and TIPPS, have gained attention in the treatment of BCS and shunt occlusion [7]. Angioplasty has a high success rate in BCS due to congenital obstruction. For restenosis, balloon dilatation can be performed. As angioplasty simulates intimal hyperplasia, the number of balloon dilatations must be limited [7]. Xu et al. [8] advocated the use of metallic stents for such angioplasty failures. SEMS placement makes the dilatation more definitive.

The drop in venous pressure is more marked and it keeps the vessel patent for a longer time than angioplasty. But growth of a hyperplastic intima around the wire may reduce the diameter of the inferior vena cava. The stent may also cross the outlet of the hepatic vein, which results in an increase of turbulent flow and may lead to thrombosis [9]. TIPPS can be performed in BCS patients to improve the clinical condition while waiting for orthotopic liver transplantation. The TIPPS procedure is relatively safe and effective but its long-term patency is limited. Fortunately TIPPS stenosis responds well to reinterventions such as balloon dilatation and stents [10]. There are limited cases in the literature of percutaneous procedures secondary to a failed shunt, as most would become eligible for transplant. In our patient, we placed a SEMS in a narrowed portocaval shunt. As an interventional procedure, SEMS produced a good long term result with clinical improvement and patency. Therefore SEMS could be the procedure of choice in occluded portocaval shunts. We propose the use of SEMS as a salvage procedure for blocked side to side portocaval H-grafts before consideration of more radical procedures like liver transplantation.

\section{Abbreviations}

TIPSS: Transjugular Intrahepatic Portosystemic Shunt; SSPCS: Side-to-side portacaval shunt; USG: Ultrasonography; BCS: Budd Chiari Syndrome; SEMS: Self expanding metallic stent

\section{Competing interests}

The authors declare that they have no competing interests.

\section{Authors' contributions}

Authors ND and $\mathrm{MH}$ - revising the article critically for important intellectual content. Authors VG and SP - drafting the manuscript. Author SS - medical management of the patient and revision of the article. Author SM - performed the angioplasty stenting and also helped in revising the article.

\section{Consent}

Written informed consent was obtained from the patient for publication of this case report and accompanying images. A copy of the written consent is available for review by the Editor-in-Chief of this journal.

\section{References}

I. Savader SJ, Venbrux AC, Osterman FA: Percutaneous intervention in portosystemic shunts in Budd-Chiari syndrome. Journal Vascular Interventional Radiology I991, 2:489-495. 
2. Orloff MJ, Orloff MS, Daily PO: Long-term results of treatment of Budd-Chiari syndrome with portal decompression. Arch Surg 1992, 127: | 182-1188.

3. Orloff MJ, Daily PO, Girard B, Orloff MS: A 27-year experience with surgical treatment of Budd-Chiari syndrome. Ann Surg 2000, 232:340-352.

4. Klein AS, Cameron JL: Diagnosis and management of the BuddChiari syndrome. Am J Surg 1990, 160:128-133.

5. Slakey D, Klein A, Cameron J: Budd-Chiari syndrome: Current management options. Hepatology 1997, 26:43-49.

6. Ringe B, Lang H, Oldhafer KJ, Gebel M, Flemming P, Georgii A, Borst HG, Pichlmayr HG: That is the best surgery for Budd-Chiari syndrome: Venous decompression or liver transplantation? A single center experience with $\mathbf{5 0}$ patients. Hepatology 1995 , 2 I: | 337-I344.

7. Bilbao JI, Pueyo JC, Barettino MD, Longo JM, Arias M, Herrero JI, Bennito A, Barettino MD, Perotti JP, Pardo F: Interventional therapeutic techniques in Budd-Chiari syndrome. Cardiovascular and Interventional Radiology 1997, 20: I I2-119.

8. Xu K, He FH, Zhang H, Zhang X, Han M, Wang C, Kaneko M, Takahashi M, Okawada T: Budd-Chiari syndrome caused by obstruction of the hepatic inferior vena cava: Immediate and 2-year treatment results of transluminal angioplasty and metallic stent placement. Cardiovascular and Interventional Radiology 1996, 19:32-36.

9. Venbrux AC, Savader SJ, Mitchell SE, Osterman FA: Interventional Management of Budd-Chiari syndrome. Seminars in Interventional Radiology 1994, I I:3 |2-320.

10. Keller FS, Barton RE, Koslin DB, Lakin PC, Mizutani PA, Peterson BD, Rösch J, Saxon RR: TIPS. In Hepatobiliary and pancreatic radiology Edited by: Gazelle GS, Saini S, Mueller PR. Thieme, New York; 1998:417-447.

Publish with Bio Med Central and every scientist can read your work free of charge

"BioMed Central will be the most significant development for disseminating the results of biomedical research in our lifetime. "

Sir Paul Nurse, Cancer Research UK

Your research papers will be:

- available free of charge to the entire biomedical community

- peer reviewed and published immediately upon acceptance

- cited in PubMed and archived on PubMed Central

- yours - you keep the copyright 